angular area of pale cold mottled skin measuring $8 \times 6 \times 10 \mathrm{~cm}$ was seen. This became gangrenous. She died four days later after repeated variceal haemorrhages. The area would probably have required skin grafting had she survived.

\section{Discussion}

The vasoconstrictor effect of vasopressin is not specific for the splanchnic circulation. Only one patient (case 5) developed obvious subcutaneous extravasation of the infusion fluid. In the remaining four patients the exact mechanism is not clear. Subclinical extravasation or diffusion of the drug through the vein wall secondary to poor flow are possibilities. Analysis of these five cases and of the four reported previously ${ }^{2-4}$ failed to elicit any common factors. Five of the nine patients had obvious extravasation of the infusion fluid, three were diabetic, and two were known to have hypertension. Two of the patients reported on previously developed gas gangrene secondary to clostridial sepsis, ${ }^{2}{ }^{3}$ but this did not occur in any of our patients.

Before 1980 it was the policy of this unit to administer vasopressin by bolus infusion of 20 units over a period of 20 minutes every three to four hours. Cutaneous gangrene did not occur with this regimen. Since 1980 vasopressin by continuous infusion has been used on about 200 occasions. Many of the patients treated require a central venous catheter for pressure monitoring, and it is our practice to use this route for the infusion of vasopressin. When vasopressin has to be infused via a peripheral vein, however, the infusion site and catheter should be covered by a transparent sterile dressing and not bandaged in the traditional fashion. The nursing staff should inspect the site at hourly intervals, and if local blanching of the skin is noted the infusion should be stopped. Although there is no proved antagonist to the vasoconstrictor effect of vasopressin we would advocate immediate flushing of the catheter with a vasodilator. Treatment with vasopressin should be continued only if absolutely necessary and then via a central catheter.

The Committee on Safety of Medicines and the manufacturers of vasopressin have not received any reports of this complication.

\section{References}

${ }^{1}$ Slotnik IL, Teigland JD. Cardiac accidents following vasopressin injection (pitressin). $\mathcal{F} A M A 1951 ; 146: 1126-9$.

${ }^{2}$ Greenwald RA, Rheingold OJ, Chiprut RO, Rogers AI. Local gangrene: a complication of peripheral pitressin therapy for bleeding esophageal varices. Gastroenterology 1978;74:744-6.

${ }^{3}$ Mogan GR, Wormser GP, Gottfried EB. Infected gangrene. A serious complication of peripheral vasopressin administration. Am $\mathcal{F}$ Gastro enterol $1980 ; 73: 426-9$.

${ }^{4}$ Wormser GP, Kornblee LV, Gottfried EB. Cutaneous necrosis following peripheral intravenous vasopressin therapy. Cutis 1982;29:249-52.

5 Child CG. The liver and portal hypertension. Philadelphia: Saunders, 1964.

(Accepted 7 November 1983)

\title{
Vertebral osteomyelitis due to coccobacilli of the HB group
}

\author{
MARK FARRINGTON，SUSANNAH J EYKYN， MARK WALKER，R E WARREN
}

\begin{abstract}
Three cases of pyogenic vertebral osteomyelitis occurred in which unusual, fastidious, Gram negative coccobacilli belonging to the "HB" group were isolated. The organisms were Haemophilus aphrophilus in case 1 , intermediate between $H$ aphrophilus and Actinobacillus actinomycetemcomitans in case 2 , and Eikenella corrodens in case 3 . All HB bacteria are sensitive to a wide range of antibiotics.
\end{abstract}

\section{Introduction}

Haemophilus aphrophilus, Eikenella corrodens, and Actinobacillus actinomycetemcomitans form the " $\mathrm{HB}$ " group of fastidious, Gram negative bacilli defined by King and Tatum. ${ }^{1}$ They are commensals of the mouth and pharynx in $\operatorname{man}^{2} 3$ but have been isolated (though infrequently and usually in mixed culture) from infections in various sites, especially those close to the

\footnotetext{
Department of Microbiology, St Thomas's Hospital Medical School, London SE1 7EH

MARK FARRINGTON, MB, lecturer

SUSANNAH J EYKYN, MB, MRCPATH, reader
}

Department of Clinical Microbiology, Addenbrooke's Hospital, Cambridge CB2 2QQ

MARK WALKER, MB, MRCPATH, senior registrar

R E WARREN, MB, MRCPATH, consultant

Correspondence to: Dr M Farrington. upper respiratory tract. We report three cases of pyogenic vertebral osteomyelitis in which HB bacteria were isolated in pure growth from spinal pus and blood cultures.

\section{Case reports}

Table I summarises the clinical details of the three patients with vertebral osteomyelitis; further features in case 1 were worthy of note. The patient, a 59 year old woman, was admitted in February 1981. She had had seronegative polyarthritis for 20 years and many previous episodes of back pain and sciatica sometimes associated with prolapse of intervertebral discs. Eight months before this admission her left hip joint had been replaced successfully with a Muller prosthesis, but two months later she had been admitted with severe back pain and right sided sciatica. During the next four days a plastic epidural catheter was maintained at the L3/4 level, through which injections of bupivacaine, methylprednisolone acetate, and methadone were given. A spike of fever to $38^{\circ} \mathrm{C}$ occurred on the day that the catheter was removed, but the site was not tender or inflamed. A myelogram obtained after injection of iophendylate showed spondylolistheses and posterior disc protrusions in the lumbar and cervical spine. Her condition improved with bedrest alone, and two months later her right hip joint was also replaced. Prophylaxis with flucloxacillin was begun preoperatively and continued for two weeks. She was discharged for convalescence.

On admission in February 1981 she looked ill and had a temperature of $37.5^{\circ} \mathrm{C}$ (table I). A drill biopsy of the $\mathrm{L} 2 / 3$ disc released $10 \mathrm{ml}$ pus under pressure, but no organisms could be seen in Gram stained smears. This procedure was followed by clinical deterioration, so empirical treatment was started with oral flucloxacillin and fusidic acid ; this was stopped after three days when a Gram negative coccobacillus subsequently identified as $H$ aphrophilus was isolated from the pus. The same organism was grown on subculture after 17 days' incubation from one of 16 blood culture bottles. Before full identification and results of sensitivity tests were available her condition 
deteriorated further; intravenous ceftazidime $1 \mathrm{~g}$ thrice daily was started, and 24 hours later $600 \mathrm{ml}$ pus was drained from the psoas abscess. This contained numerous Gram negative coccobacilli, and $H$ aphrophilus was isolated in heavy, pure growth after two days' incubation. Her condition improved, and after 11 days an oral regimen (rifampicin $450 \mathrm{mg}$ and doxycycline $100 \mathrm{mg}$ both once daily) was started and continued for three months. She was then clinically well, the white cell count was $4.9 \times 10^{9} / 1$, and the erythrocyte sedimentation rate was $15 \mathrm{~mm}$ in the first hour. She remained well.

\section{Bacteriology}

Table II compares the usual growth and biochemical characteristics of HB bacteria with those of our isolates. The carbohydrate fermentation reactions were determined in serum water media (Southern Group Laboratories) after 48 hours' incubation in air with $10 \%$ added carbon dioxide.

The first organism, $H$ aphrophilus, formed tiny, translucent, nonhaemolytic colonies after three days' incubation at $37^{\circ} \mathrm{C}$ on blood agar, grew poorly on lysed blood agar and MacConkey agar (on which it produced magenta colonies), and failed to grow on nutrient agar. There was no satellitism with Staphylococcus aureus, a variable requirement for $\mathrm{X}$ factor, and no improvement in growth with added carbon dioxide. It was sensitive to a wide range of antibiotics by disc testing including penicillins, cephalosporins, aminoglycosides, macrolides, tetracycline, and rifampicin and was resistant only to fusidic acid and clindamycin. The minimum inhibitory concentrations, determined in a serum broth, of ceftazidime, doxycycline, and rifampicin were $0.6,0.25$, and $0.12 \mathrm{mg} / \mathrm{l}$ respectively.

The second organism, which was intermediate between $A$ actinomycetemcomitans and $H$ aphrophilus, showed growth characteristics similar to those of the first on blood, nutrient, and MacConkey agars at $37^{\circ} \mathrm{C}$ in air but grew better in $5 \%$ carbon dioxide on media supplemented with serum or blood. By disc diffusion it was sensitive to ampicillin and cefotaxime but resistant to trimethoprim. Other antibiotics were not tested.

The third organism, E corrodens, formed tiny, translucent, pitting, non-haemolytic colonies on blood agar after $\mathbf{4 8}$ hours' incubation in air and produced occasional white, smooth, non-corroding colonial variants. Carbon dioxide improved growth, but the isolate grew independently of $\mathrm{X}$ and $\mathrm{V}$ factors. Minimum inhibitory concentrations of ampicillin, penicillin, and cephaloridine, determined in serum broth, were $0.6,1 \cdot 2$, and $1.2 \mathrm{mg} / 1$ respectively; variable results were found by repeated disc testing of these antibiotics and tetracycline, chloramphenicol, and erythromycin.

\section{Discussion}

There was nothing remarkable in the clinical presentations of these three cases of vertebral osteomyelitis, which is usually of insidious onset with few if any localising physical signs; the only consistent features are back pain and a raised erythrocyte sedimentation rate. ${ }^{4}$ The disease has rightly been called a "diagnostic pitfall," ${ }_{5}$ and delay in diagnosis is common. Our experience shows that the problems are compounded when fastidious, unfamiliar organisms are isolated. Vertebral osteomyelitis is most commonly caused by haematogenous spread of $S$ aureus, although a wide range of other bacteria have been isolated including coliforms (commonly in association with urinary tract infection), Pseudomonas aeruginosa (in abusers of intravenous drugs), streptococci, Brucella spp, Mycobacterium tuberculosis, fungi, and anaerobes. ${ }^{4}$ Infection may also be introduced during operations on the vertebrae or may spread direct from adjacent lesions, but vertebral osteomyelitis secondary to epidural anaesthesia or myelography has rarely been reported. ${ }^{6}$ ?

In a study of many small, fastidious, Gram negative rods submitted for identification to the Communicable Disease Center, Atlanta, organisms requiring or preferring carbon dioxide for growth on solid media and usually showing granular growth in broth were designated as the group HB, after the initials of a patient. ${ }^{1}$ The HB group was divided into four subgroups. HB-1, a facultative anaerobe that pits agar, is now known as Eikenella corrodens. HB-2 is Haemophilus aphrophilus, and $\mathrm{HB}-3$ and 4 are biochemical variants of Actinobacillus

TABLE I-Clinical details of three patients with vertebral osteomyelitis due to bacteria of the HB group

\begin{tabular}{|c|c|c|c|}
\hline & Case 1 (woman aged 59) & Case 2 (man aged 66$)$ & Case 3 (man aged 61 ) \\
\hline Presentation & $\begin{array}{l}\text { Increasing lumbar pain and sciatica } \\
\text { for } 4 \text { weeks }\end{array}$ & $\begin{array}{l}\text { Lumbar pain, sciatica, and rigors for } \\
4 \text { days }\end{array}$ & Lumbar pain for 3 weeks \\
\hline $\begin{array}{l}\text { Leucocytes }\left(\times 10^{9} / 1\right) \\
\text { Erythrocyte sedimentation rate ( } \mathrm{mm} \text { in } 1 \mathrm{st} \mathrm{h})\end{array}$ & & & $10 \cdot 3$ (78\% neutrophils) \\
\hline $\begin{array}{l}\text { Positive cultures } \\
\text { Path }\end{array}$ & $\begin{array}{l}\text { Haemophilus aphrophilus cultured from } \\
\text { drill biopsy specimen, psoas abscess, } \\
\text { and } 2 \text { out of } 16 \text { blood culture } \\
\text { bottles }\end{array}$ & $\begin{array}{l}\text { Blood cultures negative ( } 8 \text { bottles). Organ- } \\
\text { ism intermediate between Actinobacillus } \\
\text { actinomycetemcomitans and } H \\
\text { aphrophilus cultured from open bone } \\
\text { biopsy specimen after } 4 \text { weeks' } \\
\text { flucloxacillin treatment }\end{array}$ & $\begin{array}{l}\text { Eikenella corrodens cultured from } 8 \text { out } \\
\text { of } 10 \text { blood culture bottles }\end{array}$ \\
\hline Other investigations & $\begin{array}{l}\text { Erosion of L2 and } 3 \text {. Psoas abscess on } \\
\text { computed tomography }\end{array}$ & $\begin{array}{l}\text { Narrowed } \mathrm{L} 1 / 2 \text { disc space. Increased } \\
\text { uptake at } \mathrm{L} 2 \text { on }{ }^{\circ} \mathrm{m} \text { Tc bone scan }\end{array}$ & $\begin{array}{l}\text { Narrowed L2/3 disc and erosion of body } \\
\text { of L3. Increased uptake at L } 3 \text { on } \\
\because 9 \mathrm{~m} \text { T bone scan }\end{array}$ \\
\hline Treatment & $\begin{array}{l}\text { Intravenous ceftazidime } 1 \mathrm{~g} \text { thrice } \\
\text { daily for } 11 \text { days, then oral } \\
\text { rifarıpicin } 450 \mathrm{mg} \text { once daily and } \\
\text { doxycycline } 100 \mathrm{mg} \text { once da } 1 \text { ly for } \\
3 \text { months }\end{array}$ & $\begin{array}{l}\text { Oral flucloxacillin } 1 \mathrm{~g} \text { four times } \\
\text { daily for } 4 \text { weeks without } \\
\text { improvement, then intravenous } \\
\text { cefotaxime } 1 \mathrm{~g} \text { four times daily for } \\
2 \text { weeks, then oral amoxycillin } \\
500 \mathrm{mg} \text { four times daily for } 4 \text { weeks }\end{array}$ & $\begin{array}{l}\text { Oral amoxycillin } 1 \mathrm{~g} \text { thrice daily for } \\
4 \text { months }\end{array}$ \\
\hline
\end{tabular}

TABLE II-Comparison of usual biochemical characteristics of HB bacteria with those of the three isolates in this study

\begin{tabular}{|c|c|c|c|c|c|c|c|c|c|c|}
\hline \multirow{3}{*}{ Test } & \multicolumn{10}{|c|}{ Organism } \\
\hline & \multirow{2}{*}{$\begin{array}{l}\text { Haemophilus } \\
\text { aphrophilus } \\
\text { (HB-2) }\end{array}$} & \multirow{2}{*}{$\begin{array}{c}\text { Isolate in } \\
\text { case } 1\end{array}$} & \multirow{2}{*}{$\begin{array}{l}\text { Isolate in } \\
\text { case } 2\end{array}$} & \multicolumn{4}{|c|}{ Actinobacillus actinomycetemcomitans } & \multirow{2}{*}{$\begin{array}{c}\text { Eikenella } \\
\text { corrodens } \\
\text { (HB-1) }\end{array}$} & \multirow{2}{*}{$\begin{array}{c}\text { Isolate in } \\
\text { case } 3\end{array}$} & \multirow{2}{*}{ HB-5 } \\
\hline & & & & $\mathrm{HB}-3$ & Intermediate 1 & Intermediate 2 & $\mathrm{HB}-4$ & & & \\
\hline Growth on nutrient agar $\mathrm{O}$, & + & - & + & - & - & - & - & + & + & - \\
\hline Blood agar $\mathrm{O}_{2}$ & + & + & + & - & - & - & - & + & + & - \\
\hline MacConkey agar $\mathrm{O}_{2}$ & $z$ & \pm & \pm & $\bar{z}$ & - & - & - & - & NT & - \\
\hline $\begin{array}{l}\text { Oxidase } \\
\text { Catalase }\end{array}$ & $\overline{-}$ & $\bar{N} T$ & $\bar{z}$ & $\bar{t}^{*}$ & $\overline{+}^{*}$ & $\bar{t}^{*}$ & $\bar{t}^{*}$ & + & + & - \\
\hline Glucose & + & + & $\bar{t}$ & + & $\stackrel{+}{+}$ & $\begin{array}{l}+* \\
+\end{array}$ & $\begin{array}{l}+\infty \\
+\end{array}$ & $\overline{-}$ & $\bar{z}$ & $\bar{t}$ \\
\hline Lactose & + & + & - & - & - & - & - & - & - & I \\
\hline Sucrose & + & + & + & - & - & - & - & - & - & - \\
\hline Mannitol & - & + & + & + & - & + & - & - & - & - \\
\hline Xylose & - & - & NT & - & - & + & + & - & NT & - \\
\hline Trehalose & + & + & NT & - & - & - & - & - & - & $=$ \\
\hline Raffinose & + & + & - & - & - & - & - & - & NT & - \\
\hline ONPG & + & + & - & - & - & - & - & - & NT & - \\
\hline Maltose & + & + & + & + & + & + & + & - & - & - \\
\hline
\end{tabular}


actinomycetemcomitans. A later addition to the group, HB-5, has been isolated mainly from the genitourinary tract and is not discussed further. ${ }^{8}$ These fastidious organisms are difficult to isolate because they grow slowly and are easily masked by other organisms in clinical specimens containing a mixed flora. They are also hard to identify as few definitive tests are readily available. Only $E$ corrodens, with its aerobic pitting properties, is at all distinctive. In some circumstances the site of origin of the specimens or the clinical manifestations may provide a clue to the identity of the organism.

Within the HB group $H$ aphrophilus has most often been reported as causing endocarditis and brain abscess; many patients with localised infections at other sites have also had $H$ aphrophilus endocarditis. ${ }^{9} H$ aphrophilus has not previously been reported as a cause of vertebral osteomyelitis, and it has been isolated from bone or joint infections in only three previous patients. One patient, with unspecified leukaemia, had chronic osteomyelitis of the hand from which $H$ aphrophilus was isolated together with Actinomyces israelii; a second patient had $H$ aphrophilus endocarditis and septic arthritis of the acromioclavicular joint; and in the third patient, a woman whose painful shoulder had previously been injected with procaine and cortisone, $H$ aphrophilus was isolated from the shoulder joint and subdeltoid bursa. ${ }^{2}$

$A$ actinomycetemcomitans has been isolated with $A$ israelii but has also been implicated alone in destructive periodontal disease and other oropharyngeal sepsis and is recognised as a rare cause of endocarditis. ${ }^{10}$ Muhle et al described a middle aged man with lumbar vertebral osteomyelitis and axillary abscesses from both of which the organism was isolated in pure growth. ${ }^{11} \mathrm{He}$ had no predisposing local conditions or evidence of endocarditis but had poor teeth.

$E$ corrodens has been reported in mixed culture from human bite and closed fist injuries, pneumonia and lung abscess, and a variety of soft tissue abscesses (particularly in intravenous drug abusers) and is a rare cause of endocarditis. ${ }^{312-14}$ Skeletal infections with $E$ corrodens are usually of the oropharyngeal area (associated with dental disease) or of the hand after a clenched fist injury. ${ }^{12} 13$ Litwack and Borchardt, however, reported a case of tibial osteomyelitis in a previously fit middle aged man with no history of recent local trauma or dental disease; $E$ corrodens was grown alone from bone curettings. ${ }^{15}$

As organisms in the HB group are slow growing, determination of antimicrobial sensitivities by disc diffusion is unreliable. Fortunately, all the organisms are sensitive to a wide range of antibiotics; there is uniform resistance only to flucloxacillin, fusidic acid, and the lincomycins. Reports of clinical experience with specific antibiotics are few. Benzylpenicillin in combination with an aminoglycoside has been recommended for the treatment of $H$ aphrophilus endocarditis, and benzylpenicillin, chloramphenicol, or tetracycline for brain abscess. ${ }^{916}$ Several strains of $A$ actinomycetemcomitans are resistant to penicillin but do not produce detectable $\beta$ lactamase. ${ }^{217}$ In a study of the antibiotic sensitivities of 14 strains cefotaxime was found to be by far the most active $\beta$ lactam, its minimum inhibitory concentration for 13 strains being less than $0.4 \mathrm{mg} / 1 .^{18}$ Tetracycline has been recommended for the treatment of periodontal disease, and the combination of ampicillin with streptomycin for endocarditis. ${ }^{217}$ Most studies have found $E$ corrodens to be more resistant than the other $\mathrm{HB}$ bacteria to the aminoglycosides, the minimum inhibitory concentration of gentamicin for most strains being about $4 \mathrm{mg} / \mathrm{l}$. Parenteral penicillin has been recommended for eikenella infection, with tetracycline an alternative.$^{3}$ For oral treatment ampicillin is to be preferred to phenoxymethylpenicillin. ${ }^{19}$ Cefotaxime is the most active $\beta$ lactam against $E$ corrodens, $90 \%$ of strains being susceptible to $0 \cdot 12 \mathrm{mg} / 1 .^{20}$

There was no obvious dental or upper respiratory source of infection in any of these three patients. In case 1 the organism may have been introduced to the spine during myelography 0 . via the indwelling epidural catheter; alternatively this trauma may have predisposed the patient to local infection from an
$H$ aphrophilus bacteraemia originating in the mouth. The organisms isolated in cases 1 and 2 were especially hard to identify; both were biochemically atypical, and their growth on MacConkey agar suggested that they might even have been nutritionally deficient Enterobacteriaceae.

Initial treatment with new broad spectrum cephalosporins in cases 1 and 2 was apparently successful, although it is difficult to assess the role of ceftazidime in case 1 because an abscess was drained surgically. The value of an oral regimen for vertebral osteomyelitis, with the patient ambulatory, is well known. Rifampicin and doxycycline were used after initial intravenous treatment in case 1 as the organism was highly sensitive to both, they diffuse well into bone, and they are well absorbed with convenient, once daily, oral doses. Case 2 shows that empirical antistaphylococcal treatment may not be appropriate if vertebral osteomyelitis is suggested by clinical presentation, radiological examination, or bone scanning. In these circumstances, if blood cultures yield negative results, the pathogen responsible should be sought by open or needle biopsy.

We thank Dr L R Hill, of the National Collection of Type Cultures, Central Public Health Laboratory, and Dr R E Weaver, special bacteriology section, Center for Disease Control, Atlanta, Georgia, USA, for identifying the organisms; and Dr D A H Yates, $\mathrm{Mr} \mathrm{M} \mathrm{H}$ Matthewson, and Professor I Mills for permission to report these cases.

Case 3 has been reported previously. ${ }^{?}$

\section{References}

${ }^{1}$ King EO, Tatum HW. Actinobacillus actinomycetemcomitans and Haemophilus aphrophilus. F Infect Dis 1962;111:85-94.

2 Page MI, King EO. Infection due to Actinobacillus actinomycetemcomitans and Haemophilus aphrophilus. $N$ Engl 7 Med 1966;275: 181-8.

${ }^{3}$ Brooks GF, O'Donoghue JM, Rissing JP, Soapes K, Smith JW. Eikenella corrodens, a recently recognised pathogen. Medicine (Baltimore) $1974 ; 53: 325-42$

4 Sapico F, Montgomerie J. Pyogenic vertebral osteomyelitis: report of nine cases and review of the literature. Rev Infect Dis 1979;1:754-75.

5 Stone DB, Bonfiglio M. Pyogenic vertebral osteomyelitis. Arch Intern Med 1963;112:491-500.

${ }^{6}$ Katz J, Aidinis SJ. Current concepts review. Complications of spinal and epidural anaesthesia. 7 Bone foint Surg [ $\mathrm{Am}] 1980 ; 62: 1219-22$.

7 Digby JM, Kersley JB. Pyogenic non-tuberculous spinal infection. $\mathcal{f}$ Bone and foint Surgery $[B r] 1979 ; 61: 47-55$

${ }^{8}$ Weaver RE, Hollis DG. Gram-negative fermentative bacteria and Francisella tularensis. In: Lennette EH, ed. Manual of clinical microbiology. Washington, DC: American Society for Microbiology, 1980: 242-62.

${ }^{9}$ Bieger RC, Brewer NS, Washington JA. Haemophilus aphrophilus: a microbiologic and clinical review and report of 42 cases. Medicine (Baltimore) $1978 ; 57: 345-55$.

10 Frederiksen W, Kilian M. Haemophilus-Pasteurella-Actinobacillus: their significance in human medicine. In : Kilian $\mathrm{M}$, Frederiksen W, Biberstein EL, eds. Haemophilus, Pasteurella and Actinobacillus. London: Academic Press, $1981: 39-55$.

11 Muhle I, Rau J, Ruskin J. Vertebral osteomyelitis due to Actinobacillus actinomycetemcomitans. $\mathcal{F} A M A 1979 ; 241: 1824-5$.

12 Goldstein EJC, Miller TA, Citron DM, Finegold SM. Infections following clenched-fist injury: a new perspective. $\mathcal{f}$ Hand Surg 1978;3:455-7.

13 Goldstein EJC, Kirby BD, Finegold SM. Isolation of Eikenella corrodens from pulmonary infections. Am Rev Respir Dis 1979;119:55-8.

${ }^{14}$ Anonymous. HB-1 bacteria become Eikenella [Editorial]. Lancet 1973; ii : $1227-8$.

15 Litwack K, Borchardt K. Osteomyelitis caused by a Bacteroides corrodenslike organism (HB-1). Clin Med 1973;80:21-2.

${ }^{16}$ Sutter VL, Finegold SM. Haemophilus aphrophilus infections: clinical and bacteriologic studies. Ann NY Acad Sci 1970;174:468-87.

17 Slots J, Evans RT, Lobbins PM, Genco RJ. In vitro antimicrobial susceptibility of Actinobacillus actinomycetemcomitans. Antimicrob Agents Chemother 1980;18:9-12.

${ }^{18}$ Hoffler U, Niederau W, Pulverer G. Susceptibility of Bacterium actinomycetem comitans to 45 antibiotics. Antimicrob Agents Chemother $1980 ; 17: 943-6$.

${ }^{19}$ Garrod LP. Penicillins for Haemophilus infections. Br Med $\mathcal{F} 1973$;iii: 290.

20 Goldstein EJC, Cherubin CE, Shulman M. Comparison of microtitrt broth dilution and agar dilution methods for susceptibility testing of Eikenella corrodens. Antimicrobial Agents Chemother 1983;23:42-5. 